\title{
A COMPARATIVE STUDY OF EXTERNAL DACRYOCYSTORHINOSOTOMY WITH AND WITHOUT THE USE OF MITOMYCIN C
}

K. Satish1, D.N. Prakash², Meghana Tanwar³, Savita Patil4, Madhumita Gopal5, Ambika A Acharya6, Amar Kulkarni ${ }^{7}$, Mohan Setlur8

\section{HOW TO CITE THIS ARTICLE:}

K Satish, DN Prakash, Meghana Tanwar, Savita Patil, Madhumita Gopal, Ambika A Acharya, Amar Kulkarni, Mohan Setlur. "A comparative study of external dacryocystorhinosotomy with and without the use of mitomycin c". Journal of Evolution of Medical and Dental Sciences 2013; Vol. 2, Issue 43, October 28; Page: 8259-8266.

ABSTRACT: PURPOSE: To compare the results of intra-operative Mitomycin C application in DCR surgery compared to external DCR in terms of patency at the end of 6 months. METHODS: The study was conducted in the Department of Ophthalmology, KR Hospital, Mysore between January 2011 to July 2013. 60 patients who were diagnosed as chronic dacryocystitis with the obstruction at the level of the NLD were divided into two groups on the basis of simple random sampling. Thirty cases underwent DCR without Mitomycin C and thirty cases underwent DCR with intraoperative MMC application. RESULTS: The study results were tabulated in terms of symptoms (tearing), tear meniscus height and lacrimal syringing patency at the end of 6 months post-operatively. CONCLUSION: Distinctly higher success rates were achieved in patients undergoing DCR with intraoperative MMC as compared to those undergoing external DCR.

KEYWORDS: External DCR, Mitomycin C.

INTRODUCTION: Blockage of nasolacrimal duct (NLD) commonly presents with persistent bothersome epiphora and many a times discharge from the affected eyes. It may be congenital or acquired. The acquired variety presents more commonly in fifth to seventh decade of life, affecting women three times more than men $1,2,3,4$. Chronic tear stasis and secondary infection occurring in this condition can lead to acute exacerbations of dacryocystitis, mucocele, chronic conjunctivitis, corneal ulcer, orbital cellulitis in untreated cases and panophthalmitis in cases having undergone intraocular surgeries 2,5. Medical treatment consists of topical antibiotic administration and massage over lacrimal sac area which is helpful for most cases of congenital NLD obstruction only in first six months of life. But definitive treatment for chronic NLD obstruction in adults is Dacryocystorhinostomy.

Addeo Toti first described the technique of external Dacryocystorhinostomy (DCR) in 1904 1,2,4,9. This operation consisted of approaching the lacrimal sac from a skin incision and creating an anastomosis between the lacrimal sac and nasal cavity through a bony ostium. Success rate of external DCR has been reported at between 80-90\% depending upon the surgeons experience 1,3-13. Failure rate is reported to be $11-28 \%$ with average being $9.4 \%$ which necessitates improving the existing technique $6,7,14,15$.

Failure rate in external DCR is attributed to many factors like common canalicular obstruction, scarring within the anastomosis, closure of osteotomy site by membrane, adhesion of synechiae formation between ostium and middle turbinate or deviated nasal septum and malpositioned ostia 1,3,4,6,7,9-11,15. The two most frequent causes of DCR failure are common canalicular obstruction and closure of osteotomy site 6,7,14,15. These common causes of failure have been quoted in literature as end effects of fibrous tissue growth, scarring and granulation tissue 
formation which sometimes forms an occluding membrane obstructing the new drainage channel 1,3,4-7,11,15,16. Thus, if we inhibit fibrous tissue growth and scarring by applying anti-proliferative agents over the anastomosed flaps and osteotomy site, failure rate might be decreased.

A comparative study of external DCR and DCR with intra-operative MMC application will clearly establish the efficacy of Mitomycin C in improving the success rate in DCR. Hence, this prospective randomized study was undertaken to evaluate the role of Mitomycin $\mathrm{C}$ in maintaining post-operative patency of nasolacrimal passage of DCR.

AIMS \& OBJECTIVES: To compare the results of intraoperative Mitomycin C application in DCR surgery compared to conventional DCR without Mitomycin C application in terms of patency at the end of 6 months.

MATERIALS AND METHODS: All patients who presented with features chronic dacryocystitis were evaluated .Below mentioned inclusion criteria were applied and a total of 60 patients were selected.

Inclusion Criteria: All cases presenting with features of chronic dacryocystitis with NLD block. Exclusion Criteria:

1. Obstruction prior to lacrimal sac level

2. Chronic granulomatous conditions of lacrimal sac like tuberculosis, leprosy etc

3. Malignancy of lacrimal sac

4. Long standing chronic dacryocystitis with atrophic sacs

5. Ectropion/ entropion/ lower lid laxity

6. post traumatic bone deformity in nasolacrimal region(eg Le Fort Fracture II)

7. Nasal conditions like grossly deviated nasal septum, atrophic rhinitis or nasal polyps.

This prospective randomized comparative study was conducted at the Department of Ophthalmology, KR Hospital, Mysore between January 2011 to July 2013.

This study included 60 patients who were diagnosed as chronic dacryocystitis with the obstruction at the level of the NLD. The cases were divided into two groups on the basis of simple random sampling. Group A consisted of twenty cases who underwent DCR without Mitomycin C and group B consisted of twenty cases of DCR with intra operative MMC application.

Chi-square test was the statistical test used to compare the results of subjective symptoms and objective test findings got at the end of six months after DCR surger ies for both groups.

\section{PATIENT EVALUATION:}

1. Patients selected were subjected to a complete examination according to a predetermined protocol.

2. Detailed ocular and systemic history taken. A thorough ocular examination with particular reference to the lacrimal apparatus was done in all patients. A detailed ENT evaluation was done by ENT surgeon with special emphasis to rule out significant deviation of nasal septum of hypertrophied turbinate or nasal polyps.

3. A preoperative assessment of tear meniscus height was done using slit lamp after staining the tear film with 2\% Fluorescein, ROPLAS (Regurgitation on pressure over lacrimal sac area) and sac syringing was performed with normal saline and results noted. 
4. Routine blood investigations like $\mathrm{Hb}$, Bleeding time, Clotting time, urine for albumin and sugar were done.

5. All patients received a course of oral antibiotics for five days beginning a day prior to surgery.

TECHNIQUES OF DACRYOCYSTORHINOSTOMY: All patients underwent external dacryocystorhinostomy under local anaesthesia. Lacrimal and periorbital area were painted with betadine and parts draped. After anaesthetizing nasal mucosa by topical $4 \%$ xylocaine, packing of the ipsilateral nasal cavity was done with roller gauze soaked in 5 cc of $4 \%$ xylocaine with adrenaline $1: 200,000.5 \mathrm{ml}$ of lignocaine $2 \%$ with adrenaline 1:200,000 was infiltrated around lacrimal sac for anaesthsia and haemostasis.

A curvilinear incision of $10-15 \mathrm{~mm}$ length was made along the anterior lacrimal crest starting $3 \mathrm{~mm}$ above the level of medial palpebral ligament and 3mm medial to medial canthus.

The orbicularus occuli muscle fibres were separated with artery forceps and with blunt dissector. Cat's paw retractors were used to retract the edges of incision. Angular vessels were also retracted along the edge of the incision to prevent bleeding. Bony attachment of the medial canthal ligament was divided. Lacrimal fascia was incised $1 \mathrm{~mm}$ lateral to the anterior lacrimal crest. With a blunt dissector the sac was separated from the lacrimal fossa.

The periosteum overlying and medial to the anterior lacrimal crest was exposed and elevated with the help of Traquair's periosteal elevator. Lamina papyracea, the parchment like bone of the posterior half of the lacrimal fossa was fractured with the smaller end of the blunt dissector. With the help of Traquair's perio steal elevator, the nasal mucosa was stripped from lacrimal bone to avoid damage to the nasal mucosa.

An osteotomy of approximately $12.5 \times 10 \mathrm{~mm}$ was created with successive punching of bone by Cittelli's punch. Oozing of blood was controlled by packing with ribbon gauze moistened with topical Botroclot.

The upper punctum was dilated with Nettleship's punctum dilartor, Bowman's probe was passed through the upper canaliculus to confirm the position of the common canaliculus and related part if the medial sac wall.

With the No.11 Bard-Parker blade and Bowman's probe in place, lacrimal sac and nasal mucosa were opened in a ' $\mathrm{H}$ ' fashion to form a large anterior and smaller posterior flap. The Bowman's probe was removed.

In the Mitomycin C group(group B), a piece of Merocel sponge soaked in $0.2 \mathrm{mg} / \mathrm{ml}$ of Mitomycin $\mathrm{C}$ was applied over the osteotomy margins, undersurface of anterior flaps and common canalicular opening into the sac. The sponge was kept in the osteotomy site under the flaps for 5 mins. Two anterior flaps of nasal mucosa and lacrimal sac were sutured using 6-0 vicryl interrupted sutures. The sponge was removed and normal saline was used to irrigate the osteotomy site through the lower punctum.

The two ends of MPL and the incised orbicularis muscle were closed using 6-0 vicryl with interrupted sutures. The skin incision was closed by with running subcuticular suture using 6-0 vicryl.

Antibiotic ointment was instilled into the eye, the wound dressing with betadine soaked gauze and a pressure bandage applied. 
POST OPERATIVE MANAGEMENT: All patients were given systemic antibiotics and analgesics for 5 days. Antibiotic eye drops were advised to be instilled 6 times/day for 7 days.The nasal pack was removed after 24 hours, the first dressing was done at $24 \mathrm{hrs}$. Incision area inspected for any gaping, wound infection or discharge. Lacrimal syringing was done on $1^{\text {st }}$ post op day. Patients were discharged on $2^{\text {nd }}$ postop day and were asked to come for follow-up regularly. Sutures were removed on the7th postop day.

All the patients were followed-up at $1^{\text {st }}$ week, $1^{\text {st }}$ month, $3^{\text {rd }}$ month and $6^{\text {th }}$ month. At every follow up, patients were asked about watering from the eye and presence or absence of discharge. Symptoms of patients were documented at each follow-up and classified as symptom-free (no tearing), improvement and no improvement. Patency of lacrimal passage was tested by objective tests like height of tear meniscus and lacrimal syringing and the results were documented. The result of syringing was documented as patent when the patient was asymptomatic post op and was able to perceive saline in his throat after the syringing procedure without any regurgitation from the puncta (same or opposite). The result was documented as partially patent when the patient was symptomatic post op (tearing) but was able to perceive saline in his throat after the syringing procedure with some regurgitation from the puncta while the result was said to be non patent when the patient was symptomatic and unable to perceive the presence of fluid in his throat following lacrimal sac syringing. Incision area was inspected for healthy healing.

\begin{tabular}{|l|l|}
\hline 1. SUBJECTIVE SYMPTOMS & \\
\hline Tearing condition & $\begin{array}{l}\text { Symptom free( no tearing) } \\
\text { Improvement } \\
\text { No improvement }\end{array}$ \\
\hline 2. OBJECTIVE SYMPTOMS & \\
\hline \multirow{2}{*}{ Height of tear men iscus } & $\begin{array}{l}\text { Normal }(<1 \mathrm{~mm}) \\
\text { Moderated }(1 \mathrm{~mm}) \\
\text { High }(>1 \mathrm{~mm})\end{array}$ \\
\hline \multirow{2}{*}{ Irrigation } & $\begin{array}{l}\text { Patent } \\
\text { Partially patent } \\
\text { Table1: Evaluation of the results of DCR surgery }\end{array}$ \\
\hline
\end{tabular}

Failure of DCR surgery is defined as having symptoms of excessive tearing with or without associated discharge, non-patency on lacrimal sac syringing and high tear meniscus.

Success of DCR surgery is defined as having no tearing, patency on lacrimal sac syringing and normal tear meniscus.

Improvement after DCR surgery is defined as patients having improvement in watering, partial patency on lacrimal sac syringing and moderate tear meniscus.

In some patients who complained of watering and non-patency on sac syringing, osteotomy site was examined by anterior rhinoscopy. The cause for failure was identified in these patients and they were accordingly treated by appropriate medical or surgical management. 


\section{RESULTS:}

\begin{tabular}{|c|c|c|c|c|c|c|}
\hline \multirow{2}{*}{ Age in years } & \multicolumn{2}{|c|}{ Group A } & \multicolumn{2}{|c|}{ Group B } & \multicolumn{2}{|c|}{ Total } \\
\hline & No. & $\%$ & No. & $\%$ & No. & $\%$ \\
\hline $21-30$ & 15 & 50 & 14 & 46.67 & 29 & 48.33 \\
\hline $31-40$ & 9 & 30 & 12 & 40 & 21 & 35 \\
\hline $41-50$ & 3 & 10 & 3 & 10 & 6 & 10 \\
\hline $51-60$ & 3 & 10 & 1 & 3.33 & 4 & 6.67 \\
\hline Mean age & \multicolumn{2}{|c|}{31.4 yrs } & \multicolumn{2}{|c|}{$31.1 \mathrm{yrs}$} & & \\
\hline
\end{tabular}

Majority (93.33\%) of the patients were middle aged (21-50 yrs). There was no significant difference in between the two groups ( $\mathrm{p}$ value $=0.691$ ).

Maximum number of patients were between 21-30 yrs (48.33\%).

\begin{tabular}{|c|c|c|c|c|c|c|}
\hline \multirow{2}{*}{ Gender } & \multicolumn{2}{|c|}{ Group A } & \multicolumn{2}{c|}{ Group B } & \multicolumn{2}{c|}{ Total } \\
\cline { 2 - 7 } & No. & $\mathbf{\%}$ & No. & \% & No. & \% \\
\hline Male & 8 & 26.67 & 8 & 26.67 & 16 & 26.67 \\
\hline Female & 22 & 73.33 & 22 & 73.33 & 44 & 73.33 \\
\hline \multicolumn{3}{|c|}{ Table 3: Gender distribution } \\
\hline
\end{tabular}

\begin{tabular}{|c|c|c|c|c|c|c|}
\hline $\begin{array}{c}\text { Symptoms, Tear meniscus } \\
\text { height \& Patency }\end{array}$ & \multicolumn{2}{|c|}{ Group A } & \multicolumn{2}{c|}{ Group B } & \multicolumn{2}{c|}{ Total } \\
\cline { 2 - 7 } & No. & $\mathbf{\%}$ & No. & $\mathbf{\%}$ & No. & $\mathbf{\%}$ \\
\hline Successful & 26 & 86.67 & 29 & 96.67 & 55 & 91.67 \\
\hline Improvement & 3 & 10 & 1 & 3.33 & 4 & 6.67 \\
\hline No Improvement & 1 & 3.33 & 0 & 0 & 1 & 1.66 \\
\hline
\end{tabular}

Table 4: Post operative condition at 1 week

$(\mathrm{p}$ value $=0.339)$

\begin{tabular}{|c|c|c|c|c|c|c|}
\hline $\begin{array}{c}\text { Symptoms, Tear meniscus } \\
\text { height \& Patency }\end{array}$ & \multicolumn{2}{|c|}{ Group A } & \multicolumn{2}{c|}{ Group B } & \multicolumn{2}{c|}{ Total } \\
\cline { 2 - 7 } & No. & $\mathbf{\%}$ & No. & $\mathbf{\%}$ & No. & $\mathbf{\%}$ \\
\hline Successful & 25 & 83.33 & 29 & 96.67 & 54 & 90 \\
\hline Improvement & 3 & 10 & 1 & 0.33 & 4 & 6.67 \\
\hline No Improvement & 2 & 6.67 & 0 & 0 & 2 & 3.33 \\
\hline
\end{tabular}

Table 5: Post operative condition at 1 month

(p value $=0.192)$

\begin{tabular}{|c|c|c|c|c|c|c|}
\hline $\begin{array}{c}\text { Symptoms, Tear meniscus } \\
\text { height \& Patency }\end{array}$ & \multicolumn{2}{|c|}{ Group A } & \multicolumn{2}{c|}{ Group B } & \multicolumn{2}{c|}{ Total } \\
\cline { 2 - 7 } & No. & $\mathbf{\%}$ & No. & $\mathbf{\%}$ & No. & $\mathbf{\%}$ \\
\hline Successful & 22 & 73.33 & 29 & 96.67 & 51 & 85 \\
\hline Improvement & 5 & 16.67 & 1 & 0.33 & 6 & 10 \\
\hline No Improvement & 3 & 10 & 0 & 0 & 3 & 5 \\
\hline
\end{tabular}

Table 6: Post operative condition at 6 months

Success was achieved in 22 patients $(73.33 \%)$ of group $\mathrm{A}$ at the end of six months against 29 patients (96.67\%) in Group B. Near significant difference exists between these two groups ( $p$ value $=0.036$ ) 


\begin{tabular}{|c|c|}
\hline \multicolumn{1}{|c|}{ Group } & Success rate (\%) \\
\hline External DCR (Group A) & 73.33 \\
\hline External DCR with intraoperative Mitomycin C (Group B) & 96.67 \\
\hline \multicolumn{2}{|c|}{ Table 7: Success rate (at the end of 6 months after surgery) } \\
\hline
\end{tabular}

DISSCUSSION: In our prospective randomized study we found that there is a statistically significant difference ( $\mathrm{p}$ value $=0.036$ ) in the success rate between the groups i.e. in the group who underwent conventional external DCR and the group who underwent External DCR with intra operative use of Mitomycin C.

This study included 60 patients with chronic dacryocystitis with the obstruction at the level of the NLD, divided into two age and gender matched groups of equal number- The conventional group underwent DCR without Mitomycin C and the MMC group with intra operative MMC application. The results showed that after a period of follow up of 6 months, 73.33\% of cases were successfully treated according to the symptoms (tearing), tear meniscus height and the lacrimal sac syringing (Patency) in the Conventional group as compared to $96.67 \%$ in the MMC group.

Our study seems to show a slightly lower percentage of success in both groups as compared to studies done earlier as shown in Table 8:

\begin{tabular}{|c|c|c|}
\hline \multirow{2}{*}{ Study } & \multicolumn{2}{|c|}{ Success rate (\%) } \\
\cline { 2 - 3 } & Conventional group & MMC group \\
\hline Present study & 73.33 & 96.67 \\
\hline Shu L Liao \& others & 70.5 & 95.5 \\
\hline Kao CS \& others & 87.5 & 100 \\
\hline B.J. Goswami \& others & 88.8 & 96.36 \\
\hline \multicolumn{2}{|c|}{ Table 8: Comparative studies } \\
\hline
\end{tabular}

Comparing the results we obtained to the study by Shu L Liao \& others ${ }^{6}$ their conventional group showed $70.5 \%$ success against $95.5 \%$ success in MMC group. Our study results in the conventional groups are better in the conventional group (75\%) while there was a lower success rate in the MMC group (90\%) as compared to their study.

The studies done by Kao CS et $\mathrm{al}^{17}$ and B.J. Goswami \& others ${ }^{7}$ both showed higher rates of success in both groups as compared to our study which could be attributed to the smaller sample size of our study. Another limitation could have been the shorter follow up period of six months only, a longer follow up could have been desirable for the evaluation of long-term efficacy of MMC. Another factor for high success rate was repeat DCR surgery and MMC application which was done in the other studies but not in our study.

CONCLUSION: Utilizing the anti-fibroblastic activity of Mitomycin C in preventing scarring at the osteotomy site in External DCR can go a long way in preventing reblockage and in maintaining the post-operative patency of passages. Distinctly higher success rates have been achieved in patients undergoing DCR with intra-operative MMC as compared to patients undergoing Conventional DCR. 
Hence, the use of intra-operative Mitomycin C can be considered safe and simple but very effective modification of conventional external dacryocystorhinostomy.

\section{BIBLIOGRAPHY:}

1. Neard J. A. Lacrimal surgery. Section VI. In: Principles and practice of ophthalmic plastic and reconstructive surgery, Stephen Bosniak (ed.). $1^{\text {st }}$ edition, Philadelphia: WB Saunders Company 1996; 729-834

2. Duke Elder S, MacFaul P.A. Diseases of lacrimal passages. Chapter X. In: The ocular adnexa in system of ophthalmology, Duke Elder S (ed.) St,Louis: CV Mosby Company 1974;675-773

3. Illif C E. A simplified dacryocystorhinostomy, Arch Ophthal 1971; 85: 596-591

4. Pico G. A modified technique of external dacryocystorhinostomy. American Journal of Ophthalmology 1971; 72: 679-690.

5. Kersten R C, Bartley GB, Neard JA, Neuhans RW, Nowinski TS, Popham JK, B eardsley TL. Lacrimal system. Part 3. Section 7. In: Basic and clinical science course, San Franscisco, the foundation of the American Academy of Ophthalmology 2000-01; pp 221-254.

6. Liao L S, Kao S C S, Tseng J H S, Chen MS, Hou P K. Results of intr-operative Mitomycin C application on DCR. Br J Ophthalmogy 2000; 84:903-906.

7. Goswami BJ, Chakarvathy D, Kalyan Das. Mitomycin C as useful adjunct in external DCR in scar prone conditions. All India Ophthalmological Society Year Book 2002; 517-519.

8. Jones, LJ.Anatomical approach to problems of the eyelids and lacrimal apparatus. Archives of Ophthalmology 1961; 66:137-149.

9. Shin S, Thurairaja. External dacryocystorhinostomy - an end of an era? British journal of Ophthalmology 1997; 81:716-717.

10. Tarbet KJ, Custer PL. External dacryocystorhinostomy. Surgical success, patient satisfaction and economic cost. Ophthalmology 1995; 102(7):1065-70.

11. Ezra E, Restori M, Mannor GE, Rose GE. Ultrasonic assessment of rhinostomy size following External dacryocystorhinostomy. British Journal Of Ophthalmology 1998; 83:786-789.

12. Tsai C, C Kau H C ,Kao SC, Hsu WM, Liu JH. Efficacy of probing th NLD with adjunctive Mitomycin C for epiphora in adults. Ophthalmology 2002; 109:172-174.

13. Kanski JJ, Menon J. Clinical Ophthalmology. Philadelphia: Butterworth- Heinman, $5^{\text {th }}$ edition. 2003; pp. 43-56.

14. Welham RAN, Wulc AE. Management of unsuccessful lacrimal surgery. British Journal of Ophthalmology 1987; 71:152-157.

15. McLean CJ,Cree IA, Rose GE. Rhinostomies: an open and shut case? British Journal of Ophthalmology 1999; 83:1300-1301.

16. Baldeschi L, Nardi M, Hintschich CR, Koornneef L. Anterior suspended flaps: a modified approach for external DCR. British Journal Of Ophthalmology 1998; 82:790-792.

17. Kao SCS, Liao CL, Tseng JHS. Dacryocystorhinostomy with intra-operative Mitomycin C Ophthalmology1997; 104:86-91. 


\section{AUTHORS:}

1. K. Satish

2. D.N. Prakash

3. Meghana Tanwar

4. Savita Patil

5. Madhumita Gopal

6. Ambika A. Acharya

7. Amar Kulkarni

8. Mohan Setlur

\section{PARTICULARS OF CONTRIBUTORS:}

1. Associate Professor, Department of ophthalmology, K.R. Hospital, Mysore Medic al College and Res earch Institute, Mysore.

2. Assistant Professor, Department of ophthalmology, K.R. Hospital, Mysore Medic al College and Res earch Institute, Mysore.

3. Resident, Department of ophthalmology, K.R. Hospital, Mysore Medical College and Research Institute, Mysore.

4. Resident, Department of ophthalmology, K.R. Hospital, Mysore Medical College and Research Institute, Mysore.
5. Resident, Department of ophthalmology, K.R. Hospital, Mysore Medical College and Research Institute, Mysore.

6. Resident, Department of ophthalmology, K.R. Hospital, Mysore Medical College and Research Institute, Mysore.

7. Resident, Department of ophthalmology, K.R. Hospital, Mysore Medical College and Research Institute, Mysore.

8. Resident, Department of ophthalmology, K.R. Hospital, Mysore Medical College and Research Institute, Mysore.

\section{NAME ADDRESS EMAIL ID OF THE CORRESPONDING AUTHOR:}

Dr. K. Satish, Department of Ophthalmology, MMC \& RI, K.R. Hospital, Irwin Road, Mysore - 570001.

Email - drsatishkeshav@gmail.com

Date of Submission: 07/10/2013.

Date of Peer Review: 08/10/2013.

Date of Acceptance: 22/10/2013.

Date of Publishing: 23/10/2013 